\section{Commentary: Preoperative nutritional status and mortality from cardiac surgery: Do we have your attention yet?}

\author{
Brian S. Donahue, MD, PhD
}

Surgical recovery involves activation of numerous cellular processes, all of which depend on nutrient availability. Although poor nutritional status is common in surgical populations, ${ }^{1}$ nutritional assessment methods, and their concomitant decision-making, have yet to be routinely implemented in many surgical practices. The nutritional status of our cardiac surgery patients may therefore represent an opportunity for process improvement. ${ }^{2}$

The current study by Cho and colleagues ${ }^{3}$ underscores the important role of nutrition in outcomes following valve surgery. Using multivariate methods, they report significant associations of 3 nutritional indices with 1-year mortality, independent of other risk factors including disease severity. These nutritional scores can be computed from routine laboratory tests and are much easier to employ than other nutritional surveys. ${ }^{4}$ Specifically, they report that the Controlling Nutritional Status (CONUT) score carries an independent hazard ratio of 1.31 for 1-year mortality, with linearity between the nutritional score and the log of the hazard. Their findings are consistent in effect and magnitude with other data on CONUT scores and mortality: in cardiac surgery, 5,6 catheter interventions, ${ }^{7-11}$ infective endocarditis, ${ }^{12}$ and gastrointestinal cancer surgery. ${ }^{13-17}$ Studies on congenital heart surgery show strong links between

From the Division of Pediatric Cardiac Anesthesia, Departments of Anesthesiology and Pediatrics, Vanderbilt University Medical Center, Nashville, Tenn.

Disclosures: The author reported no conflicts of interest.

The Journal policy requires editors and reviewers to disclose conflicts of interest and to decline handling or reviewing manuscripts for which they may have a conflict of interest. The editors and reviewers of this article have no conflicts of interest.

Received for publication Dec 31, 2020; revisions received Dec 31, 2020; accepted for publication Jan 4, 2021; available ahead of print Jan 13, 2021.

Address for reprints: Brian S. Donahue, MD, PhD, Division of Pediatric Cardiac Anesthesia, Department of Anesthesiology, Vanderbilt University Medical Center, Monroe Carell Jr Children's Hospital at Vanderbilt, 2200 Children's Way, Nashville, TN 37232 (E-mail: brian.donahue@vumc.org).

J Thorac Cardiovasc Surg 2022;164:1150-1

$0022-5223 / \$ 36.00$

Copyright $₫ 2021$ Published by Elsevier Inc. on behalf of The American Association for Thoracic Surgery

https://doi.org/10.1016/j.jtcvs.2021.01.011

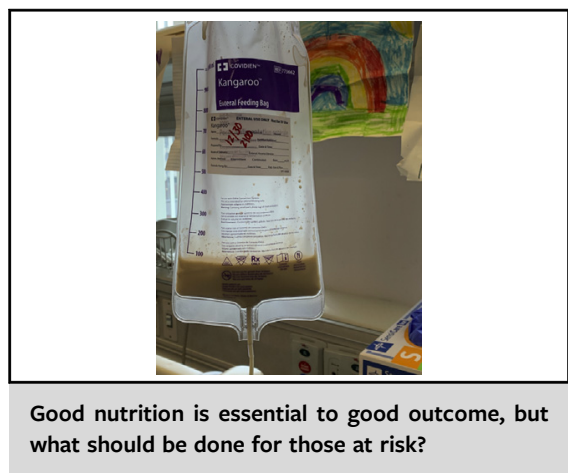

CENTRAL MESSAGE

Preoperative nutritional scores

predict 1-year survival following

valve surgery. This merges well

with the literature and should

inspire us to take seriously the

issues of perioperative nutrition.

nutrition and survival, although CONUT was not the scoring system used. ${ }^{18,19}$

With such a consistent body of literature indicating that preoperative nutritional deficiency predicts poor prognoses, what does this mean for practitioners? Perioperative risk can be assessed more accurately when nutritional status scores are included with other risk factors, specific for each practice and patient population. But although screening to identify individuals at risk is essential to nutritional optimization, ${ }^{20}$ screening is only a first step. What action should be taken when faced with a cardiac surgery patient having a low nutritional score? Action demands evidence, and the authors recognize that prospective studies are needed to address this question. To this end, data showing the benefits of targeted preoperative exercise and nutritional interventions are reported for colorectal and oncologic surgery, ${ }^{20}$ and prospective trials of nutritional interventions in cardiac surgery are ongoing. ${ }^{21,22}$

Currently, great attention is paid to adherence to Surgical Care Improvement Project guidelines for prevention of surgical-site infections. ${ }^{23}$ If we are willing to invest effort into the timing of antibiotics to prevent infection, and the development and implementation of consensus guidelines, how much more effort should we be investing into studying perioperative nutritional status, which carries a roughly similar risk, ${ }^{24}$ yet a far more serious outcome, mortality? As mentioned, quality evidence is first needed to evaluate the impact of targeted nutritional interventional in cardiac 
surgery $^{25}$; perhaps someday these data will inform the creation of other consensus guidelines for nutritional optimization. Until then, in the absence of specific nutritional guidelines for managing cardiac surgery patients at risk, practitioners should consider nutritional support as currently recommended ${ }^{26}$ for general medical and surgical intensive care unit populations and keep a watchful eye on the literature for prospective trials of nutritional interventions.

\section{References}

1. Williams JD, Wischmeyer PE. Assessment of perioperative nutrition practices and attitudes-a national survey of colorectal and GI surgical oncology programs. Am J Surg. 2017;213:1010-8.

2. Zipfel N, Groenewoud AS, Rensing B, Daeter EJ, Dijksman LM, Dambrink J-HE, et al. Selecting interventions to improve patient-relevant outcomes in health care for aortic valve disease-the intervention selection toolbox. BMC Health Serv Res. 2020;20:232.

3. Cho JS, Shim J-K, Kim K-S, Lee S, Kwak Y-L. Impact of preoperative nutritional scores on 1-year postoperative mortality in patients undergoing valvular heart surgery. J Thorac Cardiovasc Surg. 2022;164:1140-9.e3.

4. Skipper A, Coltman A, Tomesko J, Charney P, Porcari J, Piemonte TA, et al. Adult malnutrition (undernutrition) screening: an evidence analysis center systematic review. J Acad Nutr Diet. 2020;120:669-708.

5. Hara M, Fujii T, Masuhara H, Kawasaki M, Tokuhiro K, Watanabe Y. The prognostic impact of the controlling nutritional status (CONUT) score in patients undergoing cardiovascular surgery. Gen Thorac Cardiovasc Surg. 2020;68:1142-7.

6. Saito A, Amiya E, Hatano M, Shiraishi Y, Nitta D, Minatsuki S, et al. Controlling nutritional status score as a predictive marker for patients with implantable left ventricular assist device. ASAIO J. 2020;66:166-72.

7. Lee K, Ahn JM, Kang DY, Ko E, Kwon O, Lee PH, et al. Nutritional status and risk of all-cause mortality in patients undergoing transcatheter aortic valve replacement assessment using the geriatric nutritional risk index and the controlling nutritional status score. Clin Res Cardiol. 2020;109:161-71.

8. Okuno T, Koseki K, Nakanishi T, Sato K, Ninomiya K, Tomii D, et al. Evaluation of objective nutritional indexes as predictors of one-year outcomes after transcatheter aortic valve implantation. J Cardiol. 2019;74:34-9.

9. Wada H, Dohi T, Miyauchi K, Doi S, Konishi H, Naito R, et al. Prognostic impact of nutritional status assessed by the controlling nutritional status score in patients with stable coronary artery disease undergoing percutaneous coronary intervention. Clin Res Cardiol. 2017;106:875-83.

10. Wada H, Dohi T, Miyauchi K, Endo H, Tsuboi S, Ogita M, et al. Combined effect of nutritional status on long-term outcomes in patients with coronary artery disease undergoing percutaneous coronary intervention. Heart Vessels. 2018;33: 1445-52.

11. Chen SC, Yang YL, Wu CH, Huang SS, Chan WL, Lin SJ, et al. Association between preoperative nutritional status and clinical outcomes of patients with coronary artery disease undergoing percutaneous coronary intervention. Nutrients. 2020;12:1295.
12. Saito Y, Aizawa Y, Iida K, Matsumoto N, Sezai A, Tanaka M, et al. Clinical significance of the controlling nutritional status (CONUT) score in patients with infective endocarditis. Int Heart J. 2020;61:531-8.

13. Takagi K, Buettner S, Ijzermans JNM, Wijnhoven BPL. Systematic review on the controlling nutritional status (CONUT) score in patients undergoing esophagectomy for esophageal cancer. Anticancer Res. 2020;40:5343-9.

14. Takagi K, Buettner S, Ijzermans JNM. Prognostic significance of the controlling nutritional status (CONUT) score in patients with colorectal cancer: a systematic review and meta-analysis. Int J Surg. 2020;78:91-6.

15. Takagi K, Domagala P, Polak WG, Buettner S, Wijnhoven BPL, Ijzermans JNM Prognostic significance of the controlling nutritional status (CONUT) score in patients undergoing gastrectomy for gastric cancer: a systematic review and meta-analysis. BMC Surg. 2019;19:129.

16. Takagi K, Domagala P, Polak WG, Buettner S, Ijzermans JNM. Prognostic sig nificance of the controlling nutritional status (CONUT) score in patients undergoing hepatectomy for hepatocellular carcinoma: a systematic review and metaanalysis. BMC Gastroenterol. 2019;19:211.

17. Zhang Y, Zhang X. Controlling nutritional status score, a promising prognostic marker in patients with gastrointestinal cancers after surgery: a systematic review and meta-analysis. Int J Surg. 2018;55:39-45.

18. Lim CYS, Lim JKB, Moorakonda RB, Ong C, Mok YH, Allen JC, et al. The impact of pre-operative nutritional status on outcomes following congenital heart surgery. Front Pediatr. 2019;7:429.

19. Ross FJ, Radman M, Jacobs ML, Sassano-Miguel C, Joffe DC, Hill KD, et al. Associations between anthropometric indices and outcomes of congenital heart operations in infants and young children: an analysis of data from the Society of Thoracic Surgeons database. Am Heart J. 2020;224:85-97.

20. Whittle J, Wischmeyer PE, Grocott MPW, Miller TE. Surgical prehabilitation: nutrition and exercise. Anesthesiol Clin. 2018;36:567-80.

21. Ogawa M, Yoshida N, Satomi-Kobayashi S, Tsuboi Y, Komaki K, Wakida K et al. Efficacy of preoperative amino acid supplements on postoperative physical function and complications in open heart surgery patients: a study protocol for a randomized controlled trial. J Cardiol. 2019;74:360-5.

22. Efremov S, Lomivorotov V, Stoppe C, Shilova A, Shmyrev V, Deryagin M, et al. Standard vs. calorie-dense immune nutrition in haemodynamically compromised cardiac patients: a prospective randomized controlled pilot study. Nutrients. 2017;9:1264.

23. Keely Boyle K, Rachala S, Nodzo SR. Centers for Disease Control and Prevention 2017 guidelines for prevention of surgical site infections: review and relevant recommendations. Curr Rev Musculoskelet Med. 2018;11:357-69.

24. de Jonge SW, Gans SL, Atema JJ, Solomkin JS, Dellinger PE, Boermeester MA Timing of preoperative antibiotic prophylaxis in 54,552 patients and the risk of surgical site infection: a systematic review and meta-analysis. Medicine (Baltimore). 2017;96:e6903.

25. Hill A, Nesterova E, Lomivorotov V, Efremov S, Goetzenich A, Benstoem C, et al. Current evidence about nutrition support in cardiac surgery patientswhat do we know? Nutrients. 2018;10:596.

26. Taylor BE, McClave SA, Martindale RG, Warren MM, Johnson DR, Braunschweig C, et al. Guidelines for the provision and assessment of nutrition support therapy in the adult critically ill patient: Society of Critical Care Medicine (SCCM) and American Society for Parenteral and Enteral Nutrition (A.S.P.E.N.). Crit Care Med. 2016;44:390-438 